\title{
Comparison of Greenstone Digital Library and DSpace: Experiences from Digital Library Initiatives at Eastern University, Sri Lanka
}

Ravikumar, M.N. ${ }^{1}$ and Ramanan, T. $^{2}$

\begin{abstract}
On the decline of budgetary allocation for libraries, information is being made available to wider audience through alternative means, such as digital libraries and online repositories. Increasing demand for certain print materials urge libraries to exploit open-source alternatives, which are highly advantageous for libraries with scarce financial resources and voracious demand from their users. An interview survey results justified the establishment of digital library service as both students and academics, amongst other issues, recorded their inability to spare time for accessing certain print collections. In this regard, like other libraries in the country, the Library of Eastern University, Sri Lanka has initiated digital library initiatives using freely available software. Amongst a number of open-source software (OSS) available to create and manage digital library collections, Greenstone and DSpace are being experimented for developing two different types of repositories. However, these two software have slight merits and demerits over one another. This paper scrutinizes those features corresponding to the needs of and challenges faced by the Library of Eastern University, Sri Lanka (EUSL), which is in its initial stage of launching digitized collections representing both its academic works and local publications. The demand for unpublished works of students and past examinations papers is always high, hence, the Library is has started digitizing materials in demand and rare to find. This comparative analysis is solely based on experiences gained by the Library of Eastern University, Sri Lanka.
\end{abstract}

Keywords: Open-Source Software, Digital Libraries, DSpace, Greenstone Digital Library (GSDL), Electronic Repositories, Eastern University, Sri Lanka (EUSL)

\footnotetext{
${ }^{1}$ Corresponding author:

Senior Assistant Librarian, Eastern University of Sri Lanka, Sri Lanka.

Email: ravimnr@gmail.com

${ }^{2}$ Senior Assistant Librarian, Eastern University of Sri Lanka, Sri Lanka.

Email: ramanan_6@yahoo.com
} 


\section{Introduction}

Tremendous technological advancements in libraries around the world evince that libraries are inseparable entities of any institution. The importance of libraries in academic institutions cannot be underestimated in this digital era, where they gradually transform to collect, process, organize and disseminate information in electronic forms to a wider range of users. At present, information exists not only in paper-based media but diverse digital formats that has led to the emergence of many modern digital and virtual libraries. According, to the definition of Online Dictionary of Library and Information Science (ODLIS) digital libraries referred as 'A library in which a significant proportion of the resources are available in machine-readable format, rather than in print or on microform, (Reitz, 2014).

Winter and Bowen-Chang (2010) states that institutional repositories make scholarly information more accessible through the Internet, thus create global visibility for an organization's scholarly publications, whilst they pave the way for greater collaboration among researchers outside the institution. It is therefore vital for any academic institution to launch digital library services to users as far as research and development is concerned.

In Sri Lanka, considerable numbers of research and university libraries are beginning to adopt open-source digital library software to create and manage digital collections (Gamage, 2012). In this regard, majority of the university libraries have initiated their digital library collections by creating institutional repositories such as digitized thesis (ETD), past-papers and intellectual output of institutions, have been successfully carried out by using DSpace and Greenstone Digital Library (GSDL) that are open-source digital library software (Ramanan \& Ravikumar, 2012).

In similar vein, the Library of Eastern Universityof Sri Lanka creates a digital repository using OSS to store and preserve university's information assets, including unpublished theses or grey literature to expand the access. The Library of EUSL could not finalize on which software to adopt since both DSpace and GSDL are used by other university libraries. To gain practical experience, the Library has tried both options for developing 
different types of its digital collections. In fact, the aims of these two digital library management systems are different, although their domains of application do overlap. This paper highlights the experiences, difficulties and promises in DSpace and Greenstone to achieve the goals of the Library, EUSL. Furthermore, it discusses other possible opportunities for combining the advantages of these two systems for the benefit of its users.

\section{Background and Methodology}

Growing concern to create and develop digital library collections has associated with ever increasing user demands for certain types of print collections (past examination papers, newspaper clippings, theses and dissertations, and rare materials), which cannot be purchased nor duplicated. Therefore, providing digital library services will remove those barriers and increase the access to resources from distance.

With more than 95,000 titles in lending and reference sections, the Library of EUSL has as many as 3,500 dissertations, and few hundreds of rare materials. Moreover, a dozen newspaper titles that are growing amass. Based on library registration records, 218 academic staff and 2852 students make up the total user population. These ever growing collections and user population are posing challenges to render quality services within a constant physical space in the Library, which is $2160 \mathrm{~m}^{2}$.

Although the number of students enrolled per academic year steadily increases the use of resources at the Library is very poor. Low number of users per day questions the rationalization of monies spent on acquiring valuable resources. Therefore, an interview at stratified random level was executed to find out as to what the issues are causing poor library usage.

Of users who visit the Library, hundred (100) individuals from different faculties, departments, and years of study were approached with open ended questions. Their responses were pooled and categorized under five (05) major statements, which are (a) 
library is too far to reach, (b) no time to visit the library, (c) long queue at photocopy, (d) lack of seats, and (e) academics prefer to have access to materials from their desktop.

\section{Scope of the Project}

Problems faced by the library users at EUSL justify the initiation and development of digital library services at the Library of Eastern University, Sri Lanka. Hence, at present, the Library has digitized its collections using two different open-source software.

Primary objective of digital libraries is to avail materials in demand to a wider range of patrons by providing an indiscriminate access through remote login via local and worldwide computer networks. Despite the benefits from users' point-of-view, digital librarianship has eased the tasks and functions of library personnel.

Balasubramanian and Kanthimathi (2004) emphasize that traditional libraries should move up to satisfy user demands in this digital world. However, library professionals are striving with creating or capturing, storing, indexing, preserving and redistributing digitized information resources contents that are guaranteed with ease of use through web-based user interface.

With progressive developments of digital library services at the Library, EUSL, the collections need to be connected with that of other university libraries in the country. In this regard, the resources and access will be enhanced, as a result of which university's webometric rank will go up.

\section{Open-Source Digital Library Software}

Open-source software is a program whose source code is available to the general public to run, distribute, study and modify for any purpose. Moreover, it is usually distributed free under the GNU License (http://opensource.org). Nevertheless, neophytes would find it difficult to decide upon as to which software suits them best. 
Randhawa (2012) presents that there are numerous open source digital library software are available on the market, thus, the right kind of option is chosen based on user's specific need and institution's objectives. There are few library automation software that have a separate 'digital library' module which could be utilized to create digital library collections.

Since open-source digital library software derives its strength from several enabling technology and metadata based inter-operability protocols, it has gained the attention of library professionals to use it for the creation of institutional repositories and digitization activities (Singh et al., 2007).

\section{Using Greenstone Digital Library (GSDL)}

Being an important and famous open-source for digital library, GSDL software provides fabulous way of organizing information and making it available over the Internet or on compact discs. An international cooperative effort established in 2000 among three parties namely New Zealand Digital Library Projects at the University of Waikato, UNESCO and the Human Info NGO, Belgium has developed and distributed this product. GSDL can handle multilingual digital documents, with search and browse facility under GNU General Public License (http://www. greenstone.org).

Greenstone is meant for non-specialist users to produce single and personalized collections. Its model visualizes a 'librarian' who is creating collections from existing resources by comprising both 'items' and metadata and distributing them over the Web or on removable media (Witten, 2005). These features make GSDL highly suitable to preserve digitized collections like dissertations/ theses, manuscripts, rare materials, past examination papers, and other in-house documents of EUSL.

\section{Building Digital Repository on DSpace}

This software is ideal for planning, building and managing digital repositories for large institutions. DSpace has been jointly developed by Massachusetts Institute of Technology (MIT) Libraries and Hewlett-Packard (HP) and distributed under BSD Open License. This 
software supports community/ collection-based content and work flow submissions by different user communities (http://www.sourceforge.net). The first version of this software was started from 2002 and the latest version is DSpace v4.2. The development of DSpace has clearly defined rules and each user of the community can contribute to it with new functions (http://www.dspace.org).Therefore, DSpace is advantageous for academics and young researchers to upload and manage their works by themselves. This will increase the degree of collaboration among students and teachers in terms of research and publications.

\section{Technical Comparison of GSDL and Dspace}

The following contents of the article describe the similarities and dissimilarities of GSDL and DSpace digital library systems (See Table 1). Further it discusses the practical experiences obtained from both systems in the following chapters.

Table 1: Common features of GSDL and DSpace

\begin{tabular}{|c|c|c|}
\hline Features & GSDL & DSpace \\
\hline $\begin{array}{l}\text { Suitable } \\
\text { (OS) }\end{array}$ & $\begin{array}{l}\text { Windows } \\
\text { 95/98/Me/NT/2000/XP } \\
\text { Unix/Linux, and MAC OS-X }\end{array}$ & $\begin{array}{l}\text { Windows(NT/2000/XP) and All } \\
\text { POSIX (Linux/BSD/UNIX-like } \\
\text { OSs),OSX }\end{array}$ \\
\hline $\begin{array}{l}\text { Programming } \\
\text { Language }\end{array}$ & $\mathrm{C}++$, Perl, Java & Java and JSP \\
\hline Associated Software & $\begin{array}{l}\text { Apache Web server, } \\
\text { Java } 1.4 .0 \text { or above, } \\
\text { ImageMagick Software } \\
\text { Ghost scripts and } \\
\text { Web Browser }\end{array}$ & $\begin{array}{l}\text { Java JDK5 or later } \\
\text { Apache Ant } 1.6 .2 \text { or later, } \\
\text { Apache Maven } 2.0 .8 \text { or later } \\
\text { Java } 1.4 \text { or later, } \\
\text { PostgreSQL } 7.3 \text { or later, } \\
\text { Apache Tomcat } 4 . x / 5 . x \text { and } \\
\text { Web Browser }\end{array}$ \\
\hline Database (DBMS) & Its Own & PostgreSQL \\
\hline Meta data format & $\begin{array}{l}\text { Dublin Core (qualified and } \\
\text { unqualified) } \\
\text { METS } \\
\text { RFC1807 } \\
\text { NZGLS (New Zealand } \\
\text { Government Locator Service) }\end{array}$ & $\begin{array}{l}\text { Dublin Core (qualified) } \\
\text { METS }\end{array}$ \\
\hline
\end{tabular}




\begin{tabular}{|l|l|l|}
\hline & $\begin{array}{l}\text { AGLS (Australian Government } \\
\text { Locator Service) }\end{array}$ & \\
\hline Plug-in extends & Yes & Yes \\
\hline Resource \\
Identifier & No & CNRI Handles \\
\hline OAI-PMH support & Yes & Yes \\
\hline Z39.50 support & Yes & No \\
\hline $\begin{array}{l}\text { Supported } \\
\text { File formats }\end{array}$ & $\begin{array}{l}\text { doc, pdf, html,ppt, postscript, } \\
\text { jpeg, gif, video, mp3, etc }\end{array}$ & $\begin{array}{l}\text { doc, pdf, html, ppt, jpeg, gif, } \\
\text { audio, video,etc. }\end{array}$ \\
\hline $\begin{array}{l}\text { Object model (Basic } \\
\text { entity) }\end{array}$ & $\begin{array}{l}\text { Document, (which is expressed } \\
\text { in XML format) }\end{array}$ & $\begin{array}{l}\text { Item (which contains both } \\
\text { metadata and digital content) }\end{array}$ \\
\hline Multilingual Support & $\begin{array}{l}\text { Greenstone provides ready-to- } \\
\text { use multilingual interfaces that } \\
\text { are already translated in many } \\
\text { languages. }\end{array}$ & $\begin{array}{l}\text { Unicode character encoding, so } \\
\text { different languages can be } \\
\text { supported }\end{array}$ \\
\hline Multimedia support & $\begin{array}{l}\text { Greenstone permits creation of } \\
\text { non-textual content such as } \\
\text { audio, video, and pictures } \\
\text { accompanied by textual } \\
\text { description or metadata to allow } \\
\text { searching and browsing }\end{array}$ & $\begin{array}{l}\text { DSpace provides a flexible data } \\
\text { object modal. It does not allow } \\
\text { construction of very different } \\
\text { objects with independent } \\
\text { metadata sets due to its } \\
\text { database oriented architecture. }\end{array}$ \\
\hline Thumbnail Preview & Images, Audio, Video & Images \\
\hline Syndication & -- & $\begin{array}{l}\text { RSS, ATOM Authentication, } \\
\text { Shiboleth Authentication }\end{array}$ \\
\hline User Authentication & User Groups & Yes \\
\hline Statistical reporting & Yes \\
\hline
\end{tabular}

Source: GSDL and DSpace manuals and instalment guides and Tramboo, et.al (2012)

These technical features of both GSDL and DSpace are helpful for the source-code modifiers and library professionals who might customize the software for their functional platforms. Based on the above facts, creating, developing and distributing digital collection is made possible in any library with minimum requirements of ICT infrastructure. 


\section{Experience with GSDL and DSPACE at Library, EUSL}

The following are the real-time experiences gained from experiments and execution of GSDL and DSpace software in the Library of Eastern University, Sri Lanka.

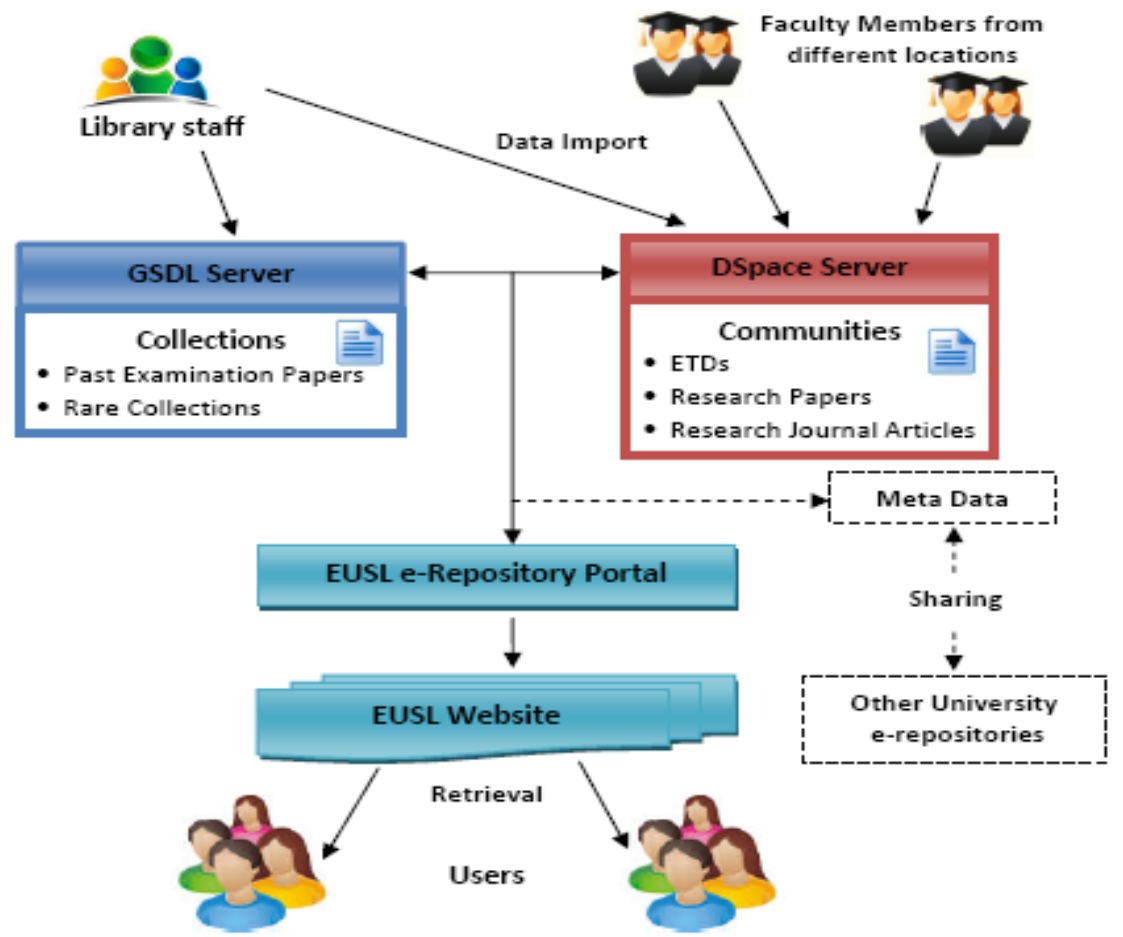

Fig.1: EUSL - Digital Library System

The technical functionalities and advantages are utilized throughout the process from installation to uploading contents. Fig: 1 clearly represents the information flow diagram of EUSL digital library system.

\section{Installation}

Both GSDL and DSpace software can be installed in all windows and Linux /Unix operating systems. According to Randhawa (2012) Greenstone has been operating on Windows since long back, whereas the Windows version of DSpace was released quite 
recently. Although these software are developed on Unix/Linux platforms, the Windows version of the same encourages large number of users to employ in their institutions.

Nevertheless, few additional software needed for the successful operation of both systems. Installation of GSDL is comparatively easier than DSpace, since Greenstone includes all necessary associated software such as Apache Web server, ImageMagick Software, Ghost scripts, etc. as a package. Therefore, library professionals who have basic computer literacy skills are able to install and configure the associated software in GSDL than on DSpace. Moreover, EUSL's server is run on Cent OS 6.0 which is Linux distributed Operating System and it is suitable for both GSDL and DSpace.

\section{Customization}

Customization and modification of web based interfaces of both systems involves editing of CSS style sheets, HTML tags and image files, etc. GSDL allows customization of presentation of collection that are based on EXtensible Stylesheet Language Transformation (XSLT) and other agents that govern the definite functions of Digital library.

In this regard during the customization HTML tags can be incorporated on GSDL which facilitate complete modification of user interface. As a result of which, collections can be hyperlinked on the digital library webpage, without navigating to different interfaces separately. On contrary, DSpace does not provide this avenue at present.

\section{Collection Development}

On GSDL, the collection defines a set of characteristics such as indexing, searching and browsing capabilities, file formats, conversion plug-ins, and entry points for the digital content import. In addition, some features are responsible for the presentation of the collection. The representation of hierarchical structure in text documents is supported for chapters, sections and paragraphs. The definition of specific sections in text document is 
implemented through special XML tags. XLinks in a document can be used to relate it with other documents or resources (Pyrounakis and Nikolaidou, 2009).

On DSpace, items and communities hold one or more collections, however, an item belongs to one or more collections, has only one owner collection. On DSpace, academics can upload their works directly from their workstations. Therefore, it is possible to assign default values for the metadata fields in a particular collection. Nonetheless, there is no support of relations or interaction between different items.

Content management on GSDL is solely executed by professional librarians. Once documents are added to a particular collection on $G S D L$, it needs rebuilding for full text indexing and browsing structures, whereas on DSpace collection building operates incrementally though recently added documents are processed in batch mode.

\section{Interface}

GSDL has two interfaces, namely Web-based and Java-based. First one operates within a web browser, and allows end users to access the digital contents so that patrons can browse, search and navigate into hierarchical objects using table of contents. Despite, presentation of documents or search results may differ depending on specified XSLTs. This option allows users to be liberal on searching through the collections. Secondly, Java-based interface, called as 'Greenstone Librarian Interface', provides facility to manage documents and collections by the administrator, perhaps a librarian.

On DSpace, a default web user interface provides access to both end users and administrators. In addition, allows users to browse across collections, view qualified Dublin Core metadata of items, and navigate to bitstreams of digitized contents. Navigation is supported through the structural metadata that may determine the ordering of complex content such as book pages or web pages. A searching interface allows the user to search using keywords. 


\section{User-Friendliness}

Both software have appropriate and convenient options with user-friendliness. For example, $G S D L$ provides multiple language interfaces for users, which can be displayed in more than 60 languages, by simply changing the 'interface language' under preference option on the user interface. Furthermore, it has a scheme that helps language maintainers keep the interfaces up-to-date when new interface features are added, which is not equipped on DSpace.

In Eastern University, Sri Lanka, student population is of tri-lingual, thus, past examination paper collections built on GSDL is highly of helpful to users of different mother tongue. Using preference option in GSDL students can easily switch to their own language. DSpace is used to store rich files of publications made by academics at EUSL.

Meanwhile, web-based interface of DSpace offers users to submit their documents directly onto the system, and define metadata for uploads, which means DSpace is more authorcentered whereas GSDL does not go with such option at the moment. Since the Internet facility is still a challenge to many entities on the campus, academics of EUSL will feel comfortable to upload and help develop the collection at their homes.

Moreover, it is possible for anyone that creates digital collections on GSDL to copy the documents and metadata onto a self-installing CD-ROM or flash drive that operates on all Windows systems. This is a convenient feature for the Library of EUSL as it has three branches where digital collections can be simply installed, especially digitized past paper collection of a particular faculty can be offered to users on demand, whereas this is not possible yet on DSpace without such features.

\section{Import and Export}

Design of the DSpace is appropriate for institutional setting, where contributors submit their documents to a common system that enforces certain standards. Its structure diverges from "communities" (e.g. faculties, departments, campuses, and programs) that contain one 
or more "collections" of digital "items". Importing and exporting metadata to and from communities, collections and items are supported on digital library built on DSpace. It also facilitates batch tools to import and export items in a simple directory structure (Witten, 2005).

Therefore, contents can be migrated between DSpace and other databases. GSDL as well does have avenue to import and export, especially when using appropriate plug-ins, documents can be imported to GSDL from other digital library systems. In this regard, using DSpace will provide possibility of sharing digitized resources across other universities in Sri Lanka that use the same software.

\section{Searching \& Browsing}

Searching on digital library developed on DSpace is constrained within a collection or community since basic metadata set is indexed by relational database as default and other defined metadata sets are indexed by Jakarta Lucene API, which supports fielded search, stemming and stop words removal. By default, browsing is offered on title, author and date of deposit. This is the reason this application was selected to develop digital collection of dissertations and theses.

On the other hand, on GSDL, browsing across catalogs is carried out using hierarchical structure. Text documents and specific metadata fields are indexed and searching is possible in whole document or for defined sections in a document, such as title, chapter, and paragraph. GSDL uses Managing Gigabytes (MG) - open-source application to support indexing and searching. This enabled a repository for past examination papers and rare materials of EUSL library.

Moreover, user can browse lists of authors, lists of titles, lists of dates, classification structures, and so on and different collections may offer different browsing facilities and even within a collection, a broad variety of browsing interfaces are available. Browsing and searching interfaces are constructed during the building process, according to collection 
configuration information. Moreover, inbuilt metadata of the documents on GSDL creates information collections that are considerably convenient to maintain.

\section{Conclusion}

Having shifted to a new building, the Library of Eastern University, Sri Lanka is intending to maximize its facilities through providing electronic resources and digital library services. However, initiating digital library services are influenced by expertise and advantages in computer and network infrastructure in a library. Besides, user demands for certain types of documents, dependability of software used, and attitude toward initiating such services also play significant role in the creation of digital repositories.

In light of increasing the access to the library resources, the digital library initiative has been commenced and progressive with the use of two digital library software. However, both applications have advantages over one another; thus, it is not possible to determine which one should be used as the digital library. The reason for using both DSpace and $G S D L$ is to increase the level of success in terms of uploads, retrieval and sharing.

Depending on the type of collection to be managed, sharing of materials, operating system platform, and time frame, the library can chose between different digital library software available of open-source market. EUSL Library used DSpace to archive the electronic thesis and dissertations (ETDs) submitted by the undergraduates, postgraduates and doctoral students of the university. In addition, publications of academics in conferences and journals are also digitized and shared on DSpace, whilst, GSDL is being used for digitizing past papers and rare collections.

Although both software are suitable to create digital repositories, the experience at the library, EUSL recommends GSDL for developing rare collection and past examination papers collection. Digital library developed on GSDL allows individual collection to be written on compact discs which can then be run as separate repositories on other computers without having the software installed. Further, GSDL features facilities real book features 
to the digitized rare material this will be more attractive to use. Whereas DSpace is more appropriate for building digital collection of thesis and institutional publications as the software provides work flow feature that allows individual departments to publish from their end.

Establishment of digital library services at the Library of Eastern University, Sri Lanka, will increase the access to in-vitro publications and other information resources that cannot be duplicated in print form. It is expected to link the Library with other entities through network to share metadata between universities that employ digital repository services. Therefore, this project will raise the webometric rank of the university.

\section{References:}

Balasubramanian, P., Muthu, A. E., \& Kanthimathi, S. (2004). Modern trends in digital library. In Digital Information Exchange: Pathways to Build Global Information Society, 22-23 January 2004, (250-252). Chennai: Indian Institute of Technology, Madras.

Chen, C. M., Chen, Y. T., Hong, C. M., Liao, C. W., \& Huang, C. M. (2012). Developing a Taiwan library history digital library with reader knowledge archiving and sharing mechanisms based on the DSpace platform. The Electronic Library, 30(3), 426442. doi: 10.1108/02640471211241681

Gamage, C. (2012). Digital Library Initiatives in University Libraries in Sri Lanka. In Professor Jayasiri Lankage Felicitation Volume (pp. 489-512). Colombo: S. Godage,

Lossau, N., Rahmsdorf, S., \& Castelli, D. (2006).Digital libraries of the future - and the role of libraries. Library Hi Tech, 24(4), 496-503.

doi:10.1108/07378830610715365

Pyrounakis, G. and Nikolaidou, M. (2009). Comparing open source digital library software, Collection of Handbook of Research on Digital Libraries, pp. 51-60, Retrieved from: www.dit.hua.gr/ mara/publications/ideaDL09a.pdf (accessed 03 January 2015) 
Randhawa, S. (2012). Open Source Software for Creation of Digital Library: A Comparative Study of Greenstone Digital Library Software \& DSpace. Indian Journal of Library and Information Science, 6 (3) (Supl.), Sept - Dec 2012. Retrieved from: http://eprints.rclis.org/19924/ (accessed 03 January 2015)

Reitz, J. M. (2014). Digital Library. ODLIS: Online dictionary for Library and Information Science. Retrieved from: http://www.abc-clio.com/ODLIS/odlis_d.aspx (accessed 14 January 2015)

Singh, S.N., Ngurtinkhuma, R.K. and Singh, Pankaj Kumar (2007). Open Source Software: a Comparative Study of Greenstone and DSpace. In Proceedings of the CALIBER 2007: 5th International Convention on Automation of Libraries in Education and Research Institutions, 2007. (pp .89-97). Retrieved from: INFLIBNET's Institutional Repository [http://hdl.handle.net/1944/517]

Tramboo, S., Humma, Shafi, S. M., \& Gul, S. (2012). A Study on the Open Source Digital Library Software's: Special Reference to DSpace, EPrints and Greenstone. International Journal of Computer Applications, 59(16), 1-9. doi: 10.5120/96294272 .

Winter, M., \& Bowen-Chang, P. (2010). Dealing with DSpace: the experience at the University of the West Indies, St Augustine. New Library World, 111(7/8), 320332. doi:10.1108/03074801011059948

Witten, H. B. D., Tansley, R. Huang C-yu, Don K,J.(2005). StoneD - A bridge between Greenstone and DSpace.D-Lib Magazine, 11(9).Retrieved from http://www.dlib.org/dlib/september05/witten/09witten.html 